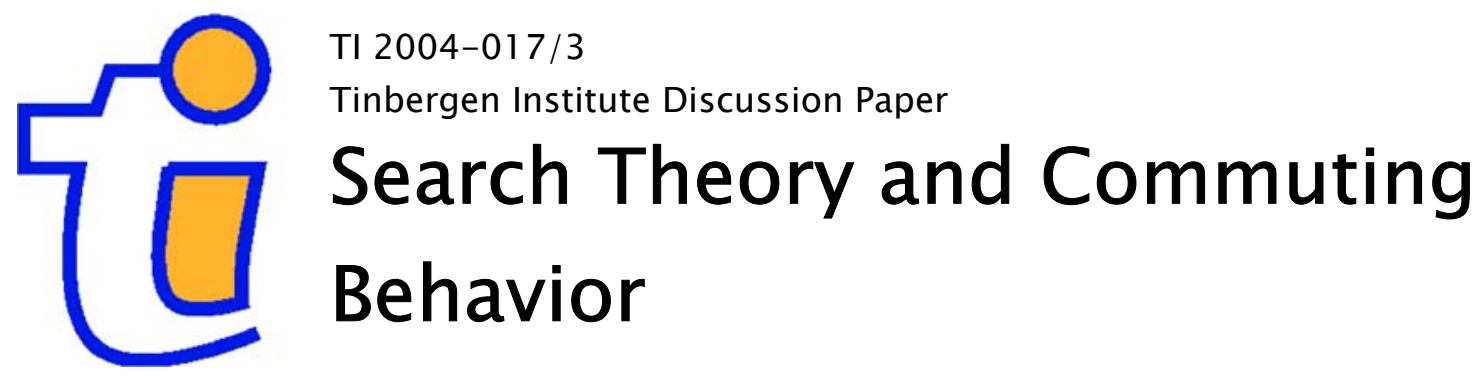

Jan Rouwendal

Department of Economics, Vrije Universiteit Amsterdam, and Wageningen University. 


\section{Tinbergen Institute}

The Tinbergen Institute is the institute for economic research of the Erasmus Universiteit Rotterdam, Universiteit van Amsterdam, and Vrije Universiteit Amsterdam.

Tinbergen Institute Amsterdam

Roetersstraat 31

1018 WB Amsterdam

The Netherlands

Tel.: $\quad+31(0) 205513500$

Fax: $\quad+31(0) 205513555$

Tinbergen Institute Rotterdam

Burg. Oudlaan 50

3062 PA Rotterdam

The Netherlands

Tel.: $\quad+31(0) 104088900$

Fax: $\quad+31(0) 104089031$

Please send questions and/or remarks of nonscientific nature to driessen@tinbergen.nl.

Most TI discussion papers can be downloaded at http://www.tinbergen.nl. 


\title{
Search theory and commuting behavior
}

\section{Jan Rouwendal}

Wageningen University, Free University, Tinbergen Institute

This version: January 21, 2004

Keywords: commuting, search theory, local labor markets JEL Classification Codes: J64, R41, R23

\begin{abstract}
In this paper I argue that search theory is a useful addition to the way economists and geographers have approached the study of commuting behavior. This is illustrated by showing that introduction of a spatial element into the standard model of job search leads to the prediction of critical isochrones. Moreover, in the context of an urban economy with decentralized employment the spatial search model predicts excess commuting. Search theory also suggests that regression towards the mean may play a confusing role in data describing the development of commutes over time, such as has been used in recent empirical work. Finally, the paper develops a simple spatial equilibrium search model in which employers set their wages optimally and searchers determine their reservation wages optimally in mutually consistent ways. The spatial element is crucial for the existence of such an equilibrium in which reservation wages of all searchers and wages set by all employers are identical.
\end{abstract}

\section{Acknowledgement}

Jos van Ommeren and four referees provided useful comments on an earlier version.

Jan Rouwendal, Department of Economics, Free University, De Boelelaan 1105, 1081 HV Amsterdam, The Netherlands, tel 31-20-4446093, fax 31-20-4446004,email jrouwendal@econ.vu.nl. 



\section{Introduction}

In this paper it will be argued that search theory makes important suggestions about possibilities to overcome some shortcomings of existing approaches used by economists and geographers. Search theory was introduced in economics by Stigler (1961) and has gained much popularity in labor economics. A standard application concerns job search of an unemployed worker. This worker is assumed to receive job offers now and then. When he receives an offer, he has to decide whether to accept it. Doing so implies the end of the search process. However, if he refuses, search continues. This model can be formalized and the optimal strategy for the searcher can be derived. Under some conditions, this strategy consists in the determination of a critical (or reservation) wage level and acceptance of the first job offer with at least this wage. The model has been extended by incorporating on-the-job search and by adding the demand side, thereby endogenizing the wage offer distribution.

The usefulness of search theory for the analysis of spatial labor markets has, of course, been realized earlier (see, for instance, Simpson, 1980, 1992 ; Rouwendal and Rietveld, 1994 and van Ommeren, 1997). It is not the purpose of this paper to review this work, but to call attention for some issues that received no attention in the existing literature. For this purpose we will use a spatial version of the standard model of job search used in labor economics in which searchers look for a job from a given residential location. First, it will be shown that this model can be used to derive critical values for acceptable commuting distances. Geographers have hypothesized the existence of such critical values in order to define critical isochrones that describe the boundaries of spatial labor markets, but did not explain their determining factors. Search theory is shown to provide useful suggestions. Second, introduction of the spatial version of the standard job search model in the context used by Hamilton to derive the implications of urban economics for commuting patterns will be shown to result in an explanation for seemingly wasteful commuting. Third, a simple extension of the standard model that allows for repeated search will be shown to generate implications for consecutive commutes that are important for empirical work. In particular, it is shown that the random element in the between vacancies and searchers implies that long commutes will often be followed by shorter ones and vice versa, as a consequence of regression towards the mean. The researcher who is unaware of this pitfall may easily conclude that workers are continually attempting to reduce long commuting distances, whereas workers are in fact adopting the same strategy in a situation that repeats itself over time. Fourth, and finally, it is shown that optimizing behavior of searchers and employers can be combined in a simple spatial equilibrium search model. In this model workers set their reservation wages and employers their offered wages optimally in mutually consistent ways. Even though all offered wages are identical, the distribution of wages net of commuting costs is non-degenerate because employment is dispersed. Similarly, the spatial dispersion of searchers causes a trade-off between a higher offered wage and the duration of a vacancy even though all workers have identical reservation wages.

The paper is organized as follows. The next section offers a short description of the economic approach and what will be called the tension approach to the analysis of commuting distances. The latter approach tends to regard long commutes as an indicator of a discrepancy between actual and ideal situations, whereas the former stresses the possibility that the disadvantages of long commutes may be compensated by, for instances, less expensive housing. In the third section the standard model of job search is introduced and placed in a spatial setting. It is then shown that the existence of critical isochrones, an important concept in the tension approach, is a prediction of that model. Moreover, it is shown that search behavior can be introduced in the setting of an urban economy with decentralized unemployment as studied by Hamilton (1982) 
and results in excess commuting that is, however, not wasteful. The modified model has both the standard outcome of the urban economics model (all commuting takes place on the ray connecting the worker's residence with the CBD) and the random matching suggested by the empirical figures as limiting cases.

In section 4 we concentrate on the relationship between two consecutively realized commutes in the context of a standard search model with layoffs. Although in this model there is no systematic relationship between these commutes, regression towards the mean can easily suggest that workers are trying to reduce long commutes. Recent empirical work has not always been aware of this effect. The model is then extended by introducing on-the-job search. One implication is that workers are willing to give up some of their income in order to realize shorter commutes. Even though this effect is present, simulations suggest that it is too weak to be of much significance for the development of actual commuting distances over time.

Section 5 considers yet another aspect that has been studied intensively in labor economics, namely the question how the wage offer distribution assumed in the standard job search model can be derived from rational employer behavior. It is shown that in the simplified setting of an 'isotropic plane' the strategies of uniformly dispersed identical workers and jobs can be coordinated in a search equilibrium. The spatial dimension of the labor market implies that all workers face a non-degenerate distribution of offered wages net of commuting costs, even though all employers set the same wage. Similarly, for employers changes in the wage affect the expected duration of the vacancy, even though all workers have identical reservation wages. Section 5 concludes.

\section{Two approaches}

This section offers a brief description of two approaches to the analysis of commuting behavior that have been used in the literature. The first is the economic approach that concentrates on the implications of rational (utility or profit maximizing) behavior in a simplified context in order to derive verifiable or testable conclusion about the functioning of urban areas. The second is an approach adopted by geographers who concentrate on some main features of the empirical information and attempt to explain them on the basis of relatively simple basic properties of human behavior, such as the desire to avoid long commutes.

\section{The economic approach}

A distinguishing feature of economic analysis is its emphasis on equilibrium outcomes. The properties of such outcomes may differ markedly from those of the basic elements of the model at hand. In the monocentric model of urban economics ${ }^{1}$ all workers dislike commuting, whereas in the model's equilibrium all are indifferent with respect to location in the city and, hence, with respect to the length of their commute. The reason for this property of the equilibrium is, of course, that there is something that compensates for longer commutes, namely the availability of cheaper housing at a larger distance from the CBD. In equilibrium the counteracting effects of a longer commute and a lower price of housing cancel so as to leave utility invariant.

A perhaps somewhat surprising aspect of the equilibrium is therefore that one of the cornerstones of the urban economic model, commuter's resistance against travelling, appears to be absent. Suppose a naïve researcher would investigate commuter's willingness to avoid long commutes by hypothesizing that those who commute to the CBD from the suburbs should be willing to decrease their commuting distances. He may easily be misled by finding that the suburban

\footnotetext{
${ }^{1}$ See e.g. Mills and Hamilton (1984) or Fujita (1989) for discussions of this model.
} 
residents are as happy with their housing/employment arrangement as those living in the inner city, and conclude that commuters do not value travel time at all. The problem is that our researcher concentrates attention on one aspect of urban reality, whereas in the urban economic model the trade-off between two aspects, house prices and commuting distance, is crucial. The economic approach thus suggests that it is dangerous to focus on a single (important) aspect of commuter's behavior, such as resistance against moving, since this may well lead to severely biased conclusions if the research is not embedded in the appropriate broader framework.

Although the monocentric model has been successful in explaining some main elements of urban structure, the empirical status of its implications for commuting behavior is embarrassing. Hamilton $(1982)^{2}$ showed that the model implies that the total distance traveled by commuters should be minimized, whereas in fact commuting patterns exhibit severe apparently wasteful or excess commuting. Since the resistance against commuting is the main driving force of the model and its implications for urban structure, this calls into question the validity of a substantial part of urban economics.

\section{The tension approach}

The economic approach is certainly not the only possible one for analyzing commuting and other disciplines have adopted different approaches. Many geographers tend to interpret the commuting distance as a tension variable. A long commute is regarded as a larger discrepancy between the actual situation and an ideal one with a small commute. For instance, Getis (1969) has proposed that consumers are relatively indifferent with respect to the length of their commuting journey as long as it remains below a certain threshold value. When the critical value is exceeded, commuters will react by adapting either their residential or their employment location. Related to this is the co-location hypothesis developed by Gordon and colleagues (see, for instance, Gordon and Wong, 1985, Gordon et al., 1991) which states that workers seek to avoid extensive congestion by periodically changing their workplace or residence. Levinson and Kumar (1994) observe that travel times in commuting in the Washington metropolitan region remained almost unchanged over the period 1957-1988, and interpreted this as evidence that jobs and housing colocate mutually 'so as to optimize travel times'. This motivates their 'rational locator hypothesis' which is a somewhat more pronounced version of the co-location hypothesis. Clark, Huang and Whithers (2003) have used this approach in a recent paper on the development of commuting distances of individual workers over time. They conclude that workers act rationally (that is: try to diminish the tension associated with long commuting) by reducing their commuting distance and time when they were initially large.

Even though the details differ, the approaches taken by the various authors just mentioned are in my view similar enough to justify grouping them under the label 'the tension approach'. In contrast to the urban economic approach, the tension approach puts no heavy emphasis on theory. Although a superficial reading of, for instance, Levinson and Kumar (1994) might suggest that they adopt a model of utility and profit maximizing economic actors of the same type as used in urban economics, this seems actually not to be the case. At least, they do not derive their rational locator hypothesis rigorously from such a model. Their analysis focuses on the empirical observations and their interpretation. This interpretation uses theoretical concepts from economics, such as rational behavior, but in a much looser way than in formal urban economics models.

\footnotetext{
${ }^{2}$ See Small and Song (1992) for a review of the debate that followed and a resolution.
} 
An important advantage of the tension approach is, of course, its close relation to empirical regularities such as the relatively small change in average commuting times over the years. This stylized fact has, as far as I am aware, never been derived in the context of an urban economics model and is therefore left unexplained by the economic approach. On the other hand, the tension approach has not much difficulty in treating excess commuting: as long the critical isochrones are not exceeded, commuting distance is of negligible importance and random matching of jobs and workers within the boundaries imposed by these isochrones is a probable outcome.

Although the tension approach has intuitive appeal, it also faces some problems. An elementary one is that it remains unclear what determines the critical isochrones and why they should remain constant over time. The observation that average commuting travel times show little variation between metropolitan areas and over time is of course important an calls for an explanation. It seems likely that such an explanation will have something to do with the reactions of workers to the spatial distributions of jobs and residences and their resistance against long commutes, but these considerations are at best the beginning of an explanation.

\section{Some discussion}

The equilibrium approach used by economists and the tension approach that is popular among geographers are, of course, not always opposites. The equilibrium in the monocentric model can only arise because the commuting distance in itself causes a disutility that must be compensated by lower house prices in order to avoid the presence of a tension that would be incompatible with equilibrium. If shocks occur in spatial arrangements of jobs and residences, such a tension should be expected to manifest itself and in such cases economists and geographers would agree in adopting a disequilibrium approach. For instance, Zax (1991) studies the reactions of workers to a move of their employment location from the city center to the city edge. Obviously, this move causes a 'shock' in the employment-housing arrangements of the workers that results in an instantaneous disequilibrium for many workers whose commuting distance has increased. As Zax shows, a number of these workers indeed responded either by moving house or by quitting. After their adjustment, the commute will be shorter than it was immediately after the shock. The economic approach and the tension approach discussed here are not the only possible approaches to analysis of commuting distances. For instance, Mokhtarian and Solomon (2001) have recently proposed the view that short commutes have positive utility. However, the discussion below will concentrate on the urban economics and tension approaches.

\section{A spatial version of the standard job search model and two applications}

In this section we introduce a spatial element into the standard model of job search and show that it can be used to derive critical isochrones and to predict excess commuting in the setting of a monocentric urban economy with decentralized employment. It may be noted that that have been other application of search model in a spatial setting, which did usually not employ the standard model of job search. For instance, Gillen and Guccione (1993) used it to find the boundaries for market areas, Harwitz et al. (1998) use a more general framework in which they considered the optimality of a reservation wage or price strategy, while Maier (1993) and Miller (1996) emphasized the spatial aspects of search problems more strongly than will be done here.

\section{The standard model of job search}

We start by a discussion of the standard model of job search. The spatial element is initially left implicit on the basis of the assumption that what matters for the workers is disposable income, 
defined as the difference between wage and commuting cost. Denoting the wage, also referred to as income, as $y$, commuting cost per kilometer as $a$ and the commuting distance as $r$, disposable income $y^{d}$ is:

$y^{d}=y-a r$

We assume that a worker's instantaneous utility $u$ is determined by this disposable income:

$u=u\left(y^{d}\right)$

Prices of consumption goods, including housing, are suppressed, since they don't play an explicit role in what follows. ${ }^{3}$ Instantaneous utility is assumed to be (strictly) increasing in disposable income. If a worker is unemployed, he receives an unemployment benefit $b$ and instantaneous utility is:

$u=u(b)$

This formulation presupposes that a jobless worker has no commuting cost. If there are such costs, for instance because the searcher has to travel for applications, they must be subtracted from the unemployment benefit.

The standard job search model concentrates on the optimal search strategy in a stationary environment. Job offers arrive at a constant rate $\lambda$. The value of disposable income corresponding to the job offer is a random drawing from a distribution (with density function $f^{*}$ ) that is assumed to be known to the searcher. In the standard model it is assumed that the worker stops searching after accepting a job. His optimal strategy can be shown to be: acceptance of the first job offer that implies a higher utility than a critical utility level $u^{r e s}$ that is determined implicitly by:

$u^{r e s}=u(b)+\frac{\lambda}{\rho} \int_{u\left(y^{d}\right)>u^{r e s}}\left(u\left(y^{d}\right)-u^{r e s}\right) f^{*}\left(y^{d}\right) d y^{d}$

In this equation $\rho$ is the rate of discount. If a searcher accepts a job, the opportunity of being offered another job with higher wage is lost. So the benefit of immediately realizing a higher income has to be traded off against the opportunity of realizing a still higher income in the future. If the wage of the offered job equals the reservation wage, the two are equal and the searcher is indifferent between acceptance and refusal. If the wage of the offered job exceeds the reservation wage, the benefits are higher than the opportunity cost and acceptance is the preferred strategy. If the wage of the offered job is lower, it is better to wait for another offer.

The standard job search model assumes that workers will keep the job they accepted indefinitely. However, a simple but useful generalization is possible if there is a fixed layoff rate, $\theta$. It implies that the time during which a worker is employed in a given job is exponentially distributed. ${ }^{4}$ After having been laid off, the worker starts searching for a new job. With this modification of the model, the expression for the reservation utility becomes:

$u^{r e s}=u(b)+\frac{\lambda}{\rho+\theta} \int_{u\left(y^{d}\right)>u^{r e s}}\left(u\left(y^{d}\right)-u^{r e s}\right) f^{*}\left(y^{d}\right) d y^{d}$

The effect of layoffs is therefore similar to that of a higher discount rate or a low arrival rate of job offers.

The standard job search model deals in a stylized way with two important labor market imperfections: limited information about job opportunities and cost associated with job switching. If these costs are high, workers who found a satisfactory job will not look for other

\footnotetext{
${ }^{3}$ The residential location and housing consumption are assumed to be fixed. An inmportant motivation for this assumption is that considerable costs are involved in moving home. See e.g. Mills (1998).

${ }^{4}$ If $t$ is the time during which a worker is employed in the same job its probability density function is $f(t)=\theta \exp (-\theta t)$.
} 
jobs, but stop searching. Moreover, searchers know the distribution of the wages of vacant jobs, but can only accept such a job once it is offered to them. Employers with vacant jobs and searchers have to find each other and because of the limited information, this only happens now and then. In a perfect labor market, there would be on-the-job search and the arrival rate would be infinitely high.

The spatial version of the job search model to be introduced below takes the residential location of the searcher as given. This is certainly not a standard assumption. For instance, the literature on monocentric models tends to take the job location as given and assumes that the residential location is adjusted to the work location. However, it is increasingly recognized that it is not selfevident, to say the least, that the job location is the most important determinant of the employment-residential arrangements of households in present day societies. One of the most important developments in this respect seems to be the increasing share of dual earner households. In such households it is not optimal to adjust the residential location to that of one of the jobs. For such households the alternative assumption adopted here, that the job location is chosen while taking the residential location as given, may be more realistic. The spatial version of the job search model that is used below may well be interpreted as referring to workers belonging to such households.

\section{Critical isochrones}

We now make the spatial aspect of the search model explicit, by treating the wage $y$ and the commuting distance $r$ as separate random variables. Their simultaneous density function will be denoted as $f(y, r)$. Using (3.1), (3.5) can be rewritten as:

$u^{r e s}=u(b)+\frac{\lambda}{\rho+\theta} \int_{u(y)>u^{\text {res }}} \int_{r: u(y-a r) \geq u^{r e s}}\left(u(y-a r)-u^{r e s}\right) f(y, r) d r d y$

According to this equation, the optimal search strategy can be interpreted as requiring that an offered job should pass two hurdles. First, the earnings should be high enough to exceed the reservation utility level at a zero commuting distance; second, the commuting distance should be short enough to make the utility associated with disposable income exceed the reservation level. The second hurdle is the result of the spatial element that has now been introduced.

In order to elaborate the spatial implications of this search strategy further, let $f^{m}(y)$ denote the marginal density of labor earnings and $f(r \mid y)$ the conditional density of commuting distances and use this to rewrite (3.6) as:

$u^{r e s}=u(b)+\frac{\lambda}{\rho+\theta} \int_{u(y)>u^{r e s}} \int_{r: u(y-a r) \geq u^{r e s}}\left(u(y-a r)-u^{r e s}\right) f^{m}(y) f(r \mid y) d r d y$

Note also that space is introduced into the model in two related, but distinct ways. First, the commuting cost plays a role via disposable income. Second, the statistical distribution of the commuting distances of offered jobs plays a role. Both elements of the model influence the distribution of commuting distances of accepted jobs, but in different ways. Commuting costs reflect the reluctance of workers to accept long commutes. However, if jobs that imply such long commutes are hardly ever offered to a searcher, the effect of commuting cost per se is limited. The distribution of the commuting distances of offered jobs depends on the spatial distribution of vacancies and searchers and on the distance decay effect in the spread of information about vacancies.

Since $u($.$) is increasing in disposable income, there is a unique critical income level y^{\text {res }}$ for which utility reaches its reservation value. The utility associated with an offered job exceeds he 
reservation utility level if and only if the level of disposable income exceeds the reservation income level. Using this allows us to rewrite (3.7) as:

$$
u\left(y^{\text {res }}\right)=u(b)+\frac{\lambda}{\rho+\theta} \int_{y>y^{\text {res }}} \int_{r<\frac{y^{r e s}-y}{a}}\left(u(y-a r)-u\left(y^{r e s}\right)\right) f^{m}(y) f(r \mid y) d r d y
$$

Let us now first consider the simple case in which the earnings $y$ associated with the jobs for which the worker is searching always have the same value. This situation may occur, for instance, as a result of specialization of the searcher into a single job type, whereas earnings levels are determined on a national scale by collective bargaining, as is common for many jobs in the Netherlands. In these circumstances (3.8) simplifies into:

$$
u\left(y^{\text {res }}\right)=u(b)+\frac{\lambda}{\rho+\theta} \int_{r<\frac{y^{r e s}-y}{a}}\left(u(y-a r)-u\left(y^{r e s}\right)\right) f(r \mid y) d r
$$

This equation says that an offered job will be accepted if the associated commuting distance is at most equal to a critical level $r^{r e s}=\left(y-y^{r e s}\right) / a$. This defines a critical isochrone. Note, however, that the search model predicts the existence of such an isochrone on the basis of the searcher's behavior in the context of an imperfect labor market, whereas Getis considered it as an elementary property of behavior. In other words, Getis postulated the existence of the critical isochrone, which is here derived from search theory. This theory also suggests that the value of the critical isochrone is dependent upon the exogenous variables of the model, such as commuting cost, unemployment benefit and layoff rate.

In the more general case in which the marginal density function of earnings is not degenerate, search theory implies that the critical isochrone depends on earnings. Workers are ready to accept jobs with a longer commute when earnings are high enough to act as a compensation.

Some conclusions may be drawn. First, we have seen that critical isochrones can be derived as a consequence of optimal search and need not be considered as a primitive concept, as was suggested by Getis. Such an approach seems to imply the necessity of a nonlinear relationship between commuting cost and the home-work distance traveled. ${ }^{5}$ Stated preference studies have found some support for gradual increases in the value of time related to the duration of a trip (see e.g.Gunn, 2001), but analyses of actual behavior do not always confirm this (see e.g. Rouwendal and van der Vlist, 2002). Moreover, data suggest that average commuting distances are relatively stable over time, but they show at the same time that there is substantial variation around this average and that the statistical distribution of commuting distances has a 'fat tail.' Nonlinearities in commuting costs would suggest that long commutes could only be observed as a consequence of temporary disequilibrium situations. Second, the suggestion that the critical isochrone depends on the other variables in the model, such as income, the unemployment benefit, the spatial distribution of job offers around the searcher's residential location, the arrival rate of these offers, et cetera can be interpreted as undermining the simplicity of the concept, but also as a motivation for further study that might deepen our understanding of commuting behavior. It suggests a number of hypotheses about observable commuting distances that are in principle open to empirical testing. The responsiveness of the critical isochrones to changes in independent variables plays a clear role in the model: it embodies the optimal reaction to such changes.

\footnotetext{
${ }^{5}$ For instance, if commuting time is unimportant whenever it remains below a threshold $k$ and the value of additional commuting time is a constant, commuting costs are 0 if commuting time $t$ is less than or equal to $k$ and to $v o t^{*}(t-k)$ when $t>k$.
} 


\section{Excess commuting}

We will now make the model developed above more concrete by placing it in the setting of an urban economics model with decentralized employment, such as was considered by Hamilton (1982). It will be shown that if we replace the perfect labor market that is conventionally assumed in that context by the assumption that unemployed workers have to search for jobs, excess commuting is an implication.

Assume that jobs and workers are located in two-dimensional space. We will usually denote the location of a job as $x=\left(x_{1}, x_{2}\right)$. The spatial labor market is a set $X$ of such job locations, which is assumed to be bounded. Jobs are distributed continuously over space and the density of job offers is denoted as $g_{x}$. It is assumed that there is a single level of earnings $y_{x}$ associated with each location.

The distance between $x$ and a residential location $z \in X$ is denoted as $d(x, z)$. It may be equal to the Euclidian distance, but other formulations (e.g. distances measured on a road network) are also possible. It has been discussed above that the optimal search strategy is to accept all jobs that offer a disposable income that exceeds the critical value $y^{\text {res }}$. This implies that the set $A_{z}$ of job locations that are acceptable to a searcher located at $\mathrm{z}$ is:

$A_{z}\left(y^{\text {res }}\right)=\left\{x \in X: y_{x}-a d(x, z) \geq y^{\text {res }}\right\}$

The value of $y^{\text {res }}(z)$ is determined implicitly by:

$u\left(y^{\text {res }}(z)\right)=u(b)+\frac{\lambda}{\rho+\theta} \iiint_{x \in A_{z}\left(y^{\text {res }}\right)}\left(u(y-a r)-u\left(y^{\text {res }}(z)\right)\right) g_{x} d x_{1} d x_{2}$

which is analogous to (3.6).

A special case of the labor market just described occurs in the city with decentralized

employment considered by Hamilton (1982) in his study of wasteful commuting (see also Mills and Hamilton, 1984). The labor market $X$ is a disk with its center (fixed arbitrarily) at $x=0$. In this city jobs are located everywhere between CBD and city edge. The earnings offered by a job located in the CBD are highest and will be denoted as $y^{*}$. Jobs located elsewhere in the city offer a wage that is equal to the difference between $y^{*}$ and the commuting cost from $\mathrm{x}$ to the CBD. ${ }^{6}$ Hence, earnings $y_{x}$ of a job at $x$ are:

$y_{x}=y^{*}-a d(x, 0)$

To see which jobs are acceptable for a worker located at $z(z \in X)$, we consider the job offers that imply a disposable income that is at least as high as $y^{\text {res }}(z)$. Subtracting the commuting cost $a d(x, z)$ from the earnings given in (2.11) gives disposable income as:

$y^{d}(z, x)=y^{*}-a[d(x, 0)+d(x, z)]$

Disposable income exceeds reservation income if the expression between square brackets is smaller than $\left(y^{*}-y^{r e s}\right) / a$. This means that the area from which jobs are acceptable to a worker in $z$ is the interior of an ellipse with $z$ and the CBD as its focal points. Since the focal points and the line segment connecting these points are always in the interior of the ellipse, they are always acceptable job locations. For these points the expression between square brackets in (3.13) is equal to the distance $d(0, z)$; for all other job locations it reaches a higher value.

Hamilton considered his model in a setting in which the labor market clears and all mutually beneficial swaps of jobs between workers take place immediately. In that situation, a worker only

\footnotetext{
${ }^{6}$ See Hamilton [1982] p. 1037: An equilibrium emerges in which [...] wages are lower in remote job locations (which offsetts reduced commuting needs of the workers).. . See also Mills and Hamilton (1984), p. 97, 98.
} 
accepts jobs that offer the highest possible disposable income. As just shown, these jobs are located on the line segment connecting $z$ and the CBD and the disposable income is $y^{\max }(z)=y^{*}$ $d(0, z)$. Hence all workers commute inwards to jobs that are closer to the CBD.

It will now be shown that this behavior is the optimal search strategy when the arrival rate of job offers is very high. To see this, consider what happens in equation (3.11) when $\lambda$ increases. It is easy to verify that as a result of such an increase, the reservation level of disposable income increases. The double integral on the right hand side of (3.11) can be written as

$p_{A}\left(E(u(y) \mid a c c)-u\left(y^{r e s}\right)\right)$ where $p_{A}$ denotes the probability that a job offer is acceptable to the searcher and the expectation concerns the utility of acceptable jobs. Since the reservation utility cannot be larger than $u\left(y^{\max }\right)$ we have from (3.11) the inequality:

$u\left(y^{\max }\right)-u(b) \leq \frac{\lambda}{\rho+\theta} p_{A}\left(E(u(y) \mid a c c)-u\left(y^{\text {res }}\right)\right)$

If $\lambda$ gets large, $p_{A}$ or the expected difference between the expected utility of acceptable jobs and the reservation utility must become small. In both cases, the only way in which this can happen is by making the reservation wage close to $y^{\max }$. If $\lambda$ gets large, $y^{\text {res }}$ must become arbitrarily close to $y^{\max }$. Using (3.13), it can easily be shown that jobs are acceptable if and only if:

$[d(x, 0)+d(x, z)] \leq \frac{y^{*}-y^{\text {res }}}{a}$

If $y^{\text {res }}$ gets close to $y^{\max }$, the numerator on the right-hand side gets close to $a d(0, z)$. Hence, the inequality can only hold if the sum of the distances on the left-hand-side gets close to $d(0, z)$. This means that the ellipse that describes the boundary of the acceptable area gets smaller. In the limiting situation only the highest possible disposable income $y^{\max }$ will be accepted, which means: only jobs located on the line segment connecting $z$ with the CBD. This is the situation that corresponds with Hamilton's model with decentralized employment.

The data studied by Hamilton (1982) suggested that actual commuting behavior was closer to another extreme, in which all jobs in the urban area are acceptable to every searcher. This opposite extreme can also be optimal in the search model considered here. Since jobs with a disposable income less than $b$ will never be accepted by searcher, we need only consider situation in which all offered jobs have a disposable income that exceeds $b$. Let $y^{\min }>b$ be the minimum possible value of disposable income of an offered job. All offered jobs will be accepted if the reservation value of income is smaller than $y^{\mathrm{min}}$. This can only happen if the following inequality holds:

$u\left(y^{\min }\right)>u(b)+\frac{\lambda}{\rho+\theta}\left(E(u(y))-u\left(y^{\min }\right)\right)$

To see this, note that equation (3.11) has to be satisfied for the actual reservation value of disposable income. Since the left hand side of (3.11) is increasing in $y^{\text {res }}$ and the right-hand side is decreasing, a 'greater than' sign should replace the equality for higher values of disposable income, such as $y^{\min }$. Note also that if all job offers are acceptable, $p_{A}$ is equal to 1 and there is no need to condition the expected utility of a job on acceptability.

In order to see that (3.16) can be valid, rewrite it as:

$\left[1+\frac{\lambda}{\rho+\theta}\right] u\left(y^{\text {min }}\right) \geq u(b)+\frac{\lambda}{\rho+\theta} E(u(y))$

If $u(b)$ can be made arbitrarily small by decreasing the unemployment benefit to values close to zero, it is always possible to induce a searcher to accept all jobs offered by making these benefits 
sufficiently low. Alternatively, for every given value of $u(b)$, inequality (3.17) will be satisfied if the arrival rate of job offers is sufficiently low or the sum of the rate of time preference and the layoff rate sufficiently large.

The huge difference between the predictions of urban economic models about commuting patterns and empirical data first observed by Hamilton, can therefore be reconciled by introducing search theory to explain the behavior of unemployed workers. It was noted above that the main reason for the popularity of search theory in labor economics is that it takes into account (albeit in a highly stylized way) some important imperfections of actual labor markets that are neglected in approaches assuming perfect information and the absence of costs associated with switching jobs. Since it is highly probable that these imperfections also play a role in urban labor markets, it is reasonable to expect that search theory may also in this field contribute to reconcile theory and fact. The analysis of the present subsection confirmed this conjecture. It suggests that the presence of substantial excess commuting does not necessarily imply that workers don't care about commuting costs, but only that they have to trade them off against other costs, such as those associated with being unemployed longer, or with switching job or house. If the problem of how to deal with such costs has an interior solution, commuting costs will be traded off against other costs and it will not be optimal to minimize just these costs. As a result, there will be excess commuting. However, this excess commuting is not purely wasteful, since it performs the useful function of allowing workers to avoid the higher costs that would be associated with trying to minimize commuting costs, while disregarding the others.

Figure 1 provides an illustration of the implications of the spatial job search model. It refers to a circular city with a radius of $10 \mathrm{~km}$. The CBD is located at the point $(0,0)$ where the two axes cross each other. The wage $y^{*}$ is equal to 1000 and commuting cost to 10 . We consider a worker who lives at a distance of $8 \mathrm{~km}$ from the city center at $(-8,0)$. The maximum disposable income that this worker is able to realize is equal to $1000-8 * 10=920$. As discussed above, this happens when his job is located exactly on the line segment connecting his residential location with the CBD. When the reservation wage equals 900, the worker is also willing to accept jobs that are outside this line segment. For instance, he is willing to accept a job located at $(.5,0)$, which gives him a (gross) wage equal to 995 , and since the commute is $8.5 \mathrm{~km}$, disposable income is equal to 910, which exceeds the reservation wage. If his reservation wage is higher, the area from which jobs are acceptable to him decreases. The figure shows the case in which the reservation wage equals 917.5. When the reservation wage is sufficiently low, the searcher is willing to accept jobs all over the city. The figure shows the acceptable area when the reservation wage equals 750 . With this reservation wage a jobs that is located at $(8,0)$, that is as far from the CBD as the worker's residential location, but in the opposite direction is acceptable. This job gives a gross income of 920 and after subtraction of the commuting cost of 160 a disposable income of 760 remains, that exceeds the reservation wage. Excess commuting may imply reverse commuting (that is commuting towards the edge of the city). It is also noteworthy that a searcher who is willing to accept jobs all over the city and who lives close to its edge is also willing to accept jobs outside the city at a considerably lower wage, provided they are not too far from his residential location. For instance, the worker considered in Figure 1 would accept a job located at $(-15,0), 7$ $\mathrm{km}$ from his residential location with a gross wage of 850 , even though he has to commute $7 \mathrm{~km}$, implying a disposable income of 780 . 


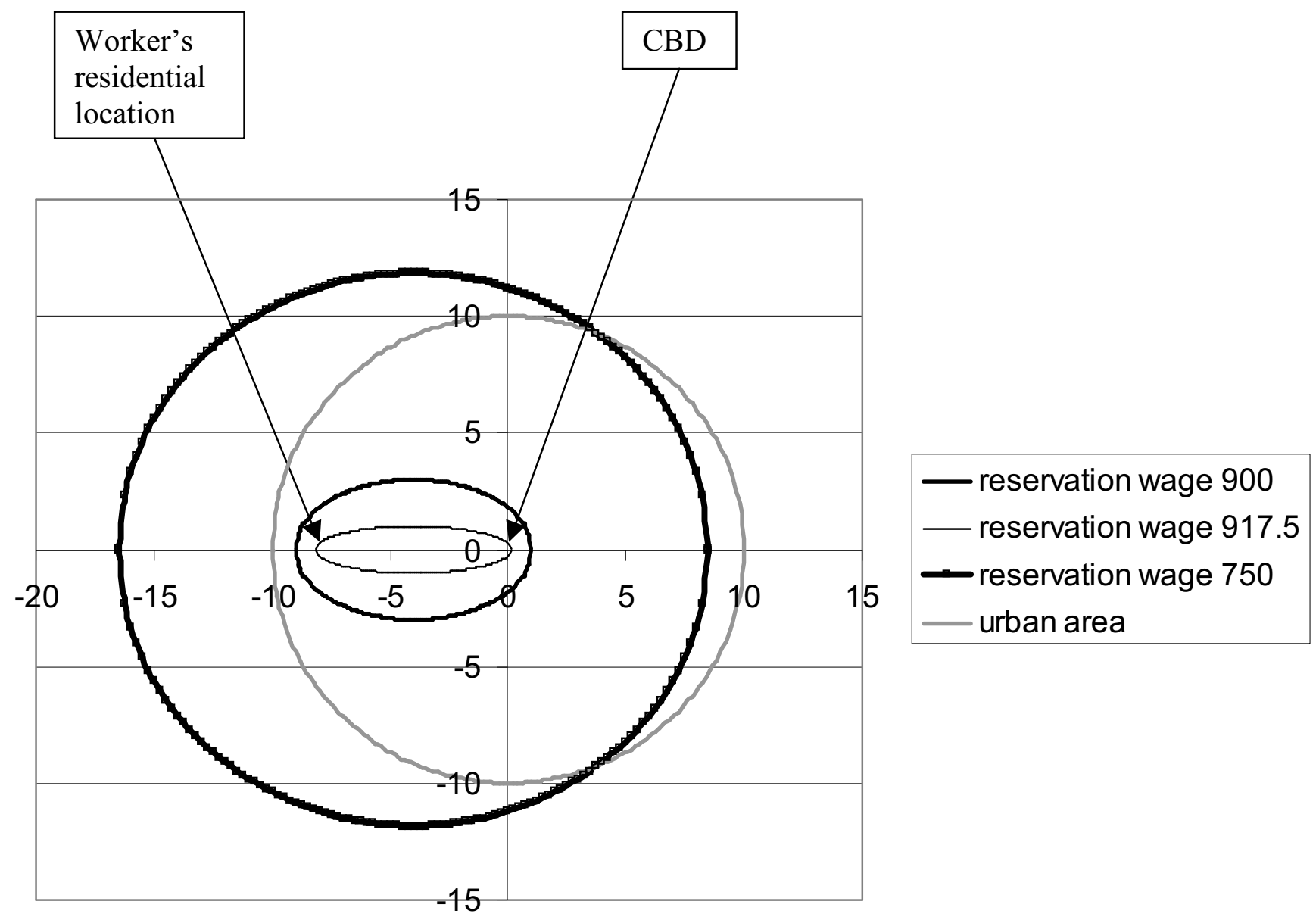

Figure 1 Boundaries of acceptable areas for job search with different reservation wages

Before closing this section it should, however, be noted that the introduction of search theory in the urban economics model was limited to the supply side of the market, whereas on the demand side we maintained the assumptions made by Hamilton, which are based on perfect competition. A further elaboration, which is left for future work, would be to consider optimal employer behavior in the setting of a labor market with search. If it takes time to find workers applying for vacant jobs, jobs may be vacant for a substantial period and this may induce employers to reconsider the optimality of the wage they offer and the location they have chosen. In section 4 of this paper we will undertake an investigation into spatial equilibrium search models in a different spatial setting, but a full consideration in the context of a monocentric model with decentralized unemployment is outside the scope of the present paper.

\section{The development of commutes over time}

In this section we consider the sequence of commutes that results over a worker's career. We take the model of the previous section as our starting point. We go on and extend it with on-the-job search. 
The sequence of commutes in a model with layoffs

The predictions of the standard search model with layoffs are in a sense trivial: in a stationary environment without on-the-job search history repeats itself. The optimal search strategy of a worker who has been laid off is always equal, and therefore the expected value of the commuting distance will also be equal in each search. This means that there is no systematic development of the commuting distance over time. The sequence of commuting distances consecutively realized by a worker is a series of random drawings from a given distribution.

However, it is worthwhile to point out that such a sequence of commuting distances shows regression towards the mean. Since the expected value of the commuting distance is equal in every search, long commutes are likely to be followed by shorter ones and vice versa. To the unwary observer, this can easily give the impression that workers tend to reduce long commutes. For instance, Clark et al.(2003) interpret such regularity as evidence that 'workers act rationally by reducing their commuting distance and time when they were initially large.' In the context of the search model of the previous section this phenomenon has nothing to do with such intentional reductions, but is simply a property of the randomness of the process involved.

In order to show how misleading the figures can be, we develop a simulation model that is a special case of the search model presented above. We specify utility as being equal to disposable income:

$$
\begin{aligned}
u\left(y^{d}, r\right) & =y^{d} \\
& =y-a r
\end{aligned}
$$

If the variable cost of travelling 1 kilometer is .10 euro (as seems reasonable for car travel) and a full time worker makes a round trip five days per week and four weeks per month, then $a$ is equal to $.10 * 2 * 5 * 4=4$ euros per month, plus the time cost involved. The time cost depends on the speed. At 50 kilometers an hour, 1 kilometer takes $(1 / 50) * 2 * 5 * 4=.8$ hours per month. The value of time is 7.5 euro per our, and the time cost of commuting one kilometer is therefore 6 euro. That implies that $a$ equals $4+6=10$ euro.

The marginal distribution of incomes is lognormal. The expected value of the lognormal is $\exp \left(\mu+\sigma^{2} / 2\right)$ and its variance $\exp \left(2 \mu+\sigma^{2}\right)\left(\exp \left(\sigma^{2}\right)-1\right)$. Parameter values were chosen so as to make the expected income of a job offer equal to 2,000 euro per month and its standard deviation to 500 euro. $^{7}$ The unemployment benefit is equal to 1,000 euro per month.

Table 1 Comparison of initial and subsequent commutes

\begin{tabular}{lcccc}
\hline $\begin{array}{l}\text { Class } \\
(\mathrm{km})\end{array}$ & Initial commute & $\begin{array}{l}\text { Next commute same or } \\
\text { shorter }\end{array}$ & Next commute longer & Next commute \\
\hline $1-5$ & 158 & 42 & 116 & 142 \\
$5-10$ & 165 & 101 & 64 & 164 \\
$10-15$ & 82 & 71 & 11 & 116 \\
$15-20$ & 50 & 46 & 4 & 50 \\
$20-25$ & 29 & 28 & 1 & 21 \\
$25-30$ & 10 & 10 & 0 & 3 \\
$\geq 30$ & 6 & 6 & 0 & 4 \\
$n$ & 500 & 304 & 196 & 500 \\
Average & 9.28 & & & 9.21 \\
\hline
\end{tabular}

Note. The table is based on 2 drawings from the acceptable wage offer distribution for 500 workers.

\footnotetext{
${ }^{7}$ The implied parameters for the lognormal distribution are $\mu=7.57$ and $\sigma=.246$.
} 
Commuting distances are, conditional on income, gamma distributed and it is assumed that the conditional distribution is independent of income. Parameter values for this distribution were determined by assuming that vacancies arise homogeneously in two-dimensional space and get more easily known to a searcher if they are located close to his residential location. The average commuting distance of an offer that arrives at a worker was assumed to be equal to 10 kilometers. ${ }^{8}$ The ratio $\lambda /(\rho+\theta)$ is equal to .1. Job offers are scarce and searchers impatient or the layoff rate is high. With these parameter values the reservation value of disposable income equals 1470. A job offering this monthly wage will be accepted if it is located 'around the corner.' Jobs with higher wages are also accepted at larger distances. For instance, the searcher is willing to commute 3 kilometers if the monthly wage equals 1500,8 if the monthly wage equals 1550 , et cetera.

Table 1 shows an implication of the search strategy. It presents the results of two subsequent independent random drawings from the distribution of acceptable wage offers, that is of combinations of an income and a commuting distance for which disposable income is higher than its reservation value. The second column of the table gives the frequency distribution of the commutes of the first drawings, the last column gives the same distribution for the second drawings. Columns 3 and 4 indicate for how many of the commutes reported in the second column the second drawing has a commute that is 'of the same length or shorter' or 'longer', respectively. Hence these two columns add up to column 2. The table shows clearly that long commutes in the first drawing are often followed (in the second drawing) by commutes that are shorter or belong to the same class, whereas short commutes are sometimes followed by longer ones. Although this Table might easily suggest that workers with long commutes dislike such a situation and will therefore choose a shorter commute in their next job, it will be clear from the way these data are generated that this is actually not the case: the two drawings are independent of each other. The only reason why jobs end is that there is a fixed layoff rate and new commutes are accepted as a consequence of exactly the same strategy that resulted in the original commutes. The suggestion of a negative effect of long initial commutes on the length of the subsequent commute in the Table is caused by the fact that according to the search model the commuting distance is a random variable. If two independent drawings from this distribution are compared, and the first drawing is larger than its mode, the probability that the next drawing is smaller exceeds $50 \%$. Similarly, if the commuting distance of the first drawing is larger than its expected value, the expected value of the commute of the second drawing is smaller than the initial commuting distance. That the apparent effect of the initial commute on the length of the subsequent commute is only a statistical artifact is also illustrated by the fact that the average length of the initial commutes equals 9.28 kilometers, whereas that of the second commute equals 9.21 kilometers. The difference is only due to the fact that for 500 drawings the sample mean still shows some variance around its expected value.

This point seems not always well understood. Figures 2,3,5 and 6 of Clark et al. (2003) present information that is similar to that of columns 2 and 3 of Table 1 above. Their observation that '[a]nalyzing the results (of changes in residence, JR) by the pre-move commute reveals a distinct pattern in which households with longer commutes before the move almost always reduced their commuting distance' might well be the result of regression towards the mean, as in Table 1. Unfortunately, Clark et al. do not present information about the average commuting distance of

\footnotetext{
${ }^{8}$ The implied parameters for the gamma distribution are $\alpha=2, \beta=5$.
} 
workers who changed residence before and after the move. If workers deliberately reduce their long commutes, this would imply that the average commuting distance must fall significantly. However, such a decrease in the average commuting distance is in fact inconsistent with an approach that emphasizes the fact that commuting distance are constant over time. The real problem seems to be that the tension approach emphasizes the reasons why workers avoid long commutes and want to reduce such commutes once they are realized, but does not explain why such commutes will ever be accepted. Search theory gives such an explanation: in order to avoid long periods of unemployment, workers are willing to accept long commutes.

It may, of course, be argued that the search model that has been used in constructing Table 1 has its own weaknesses. A potentially important one is that it does not incorporate on-the-job search. Workers may indeed accept long commutes in order to end a period of unemployment, but remain searching after becoming employed in order to shorten their commutes.

Income $y$

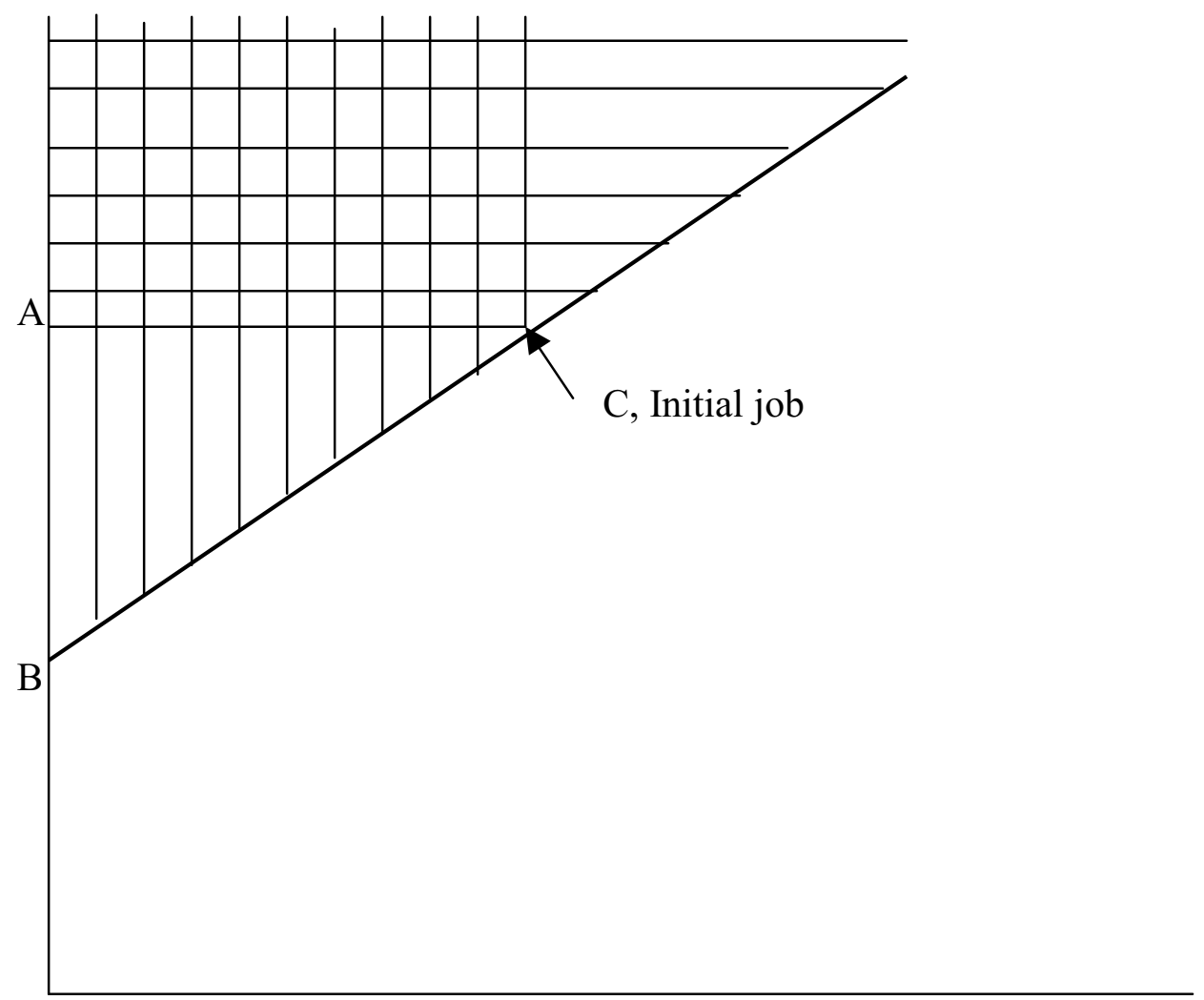

Commuting distance $r$

Figure 2 Acceptable job offers

On the job search

In order to deal with the phenomenon that workers often switch jobs without becoming unemployed, we have to allow workers to continue searching after having accepted a job. If there are no costs associated with switching jobs, the optimal strategy for the worker in this case is to accept every job offer that implies an improvement, that is: a higher value of instantaneous 
utility. Since we continue to assume that housing consumption and residential location are fixed for each worker, a higher instantaneous utility implies a higher disposable income.

If the model is extended in this way, there is a real effect of the initial commuting distance on the subsequent commuting distance. It is possible that workers accept another job only because it implies a shorter commute. This happens if the disposable income implied by the job offer is higher than it is in the worker's present situation only because the commuting distance is shorter. In other words: the worker is ready to accept a job offer with a wage that is lower than or equal to the wage he earns presently, provided that the decrease in the commuting distance compensates for this income loss.

Figure 2 illustrates this effect for the specifications used in the simulation model of the previous subsection. In this figure an initial combination of a commuting distance and an income is indicated. The boundary between acceptable and non-acceptable job offers is the straight line through the initial combination with slope $a$. Other combinations of income and commuting distance can be attractive to this worker if they offer a higher income (indicated by horizontal lines) or a shorter commuting distance (indicated by vertical lines), or both. Job offers that are only attractive because of their shorter commute are combination of income and commuting distances in the triangle with corners $\mathrm{A}, \mathrm{B}$ and the initial job, $\mathrm{C}$.

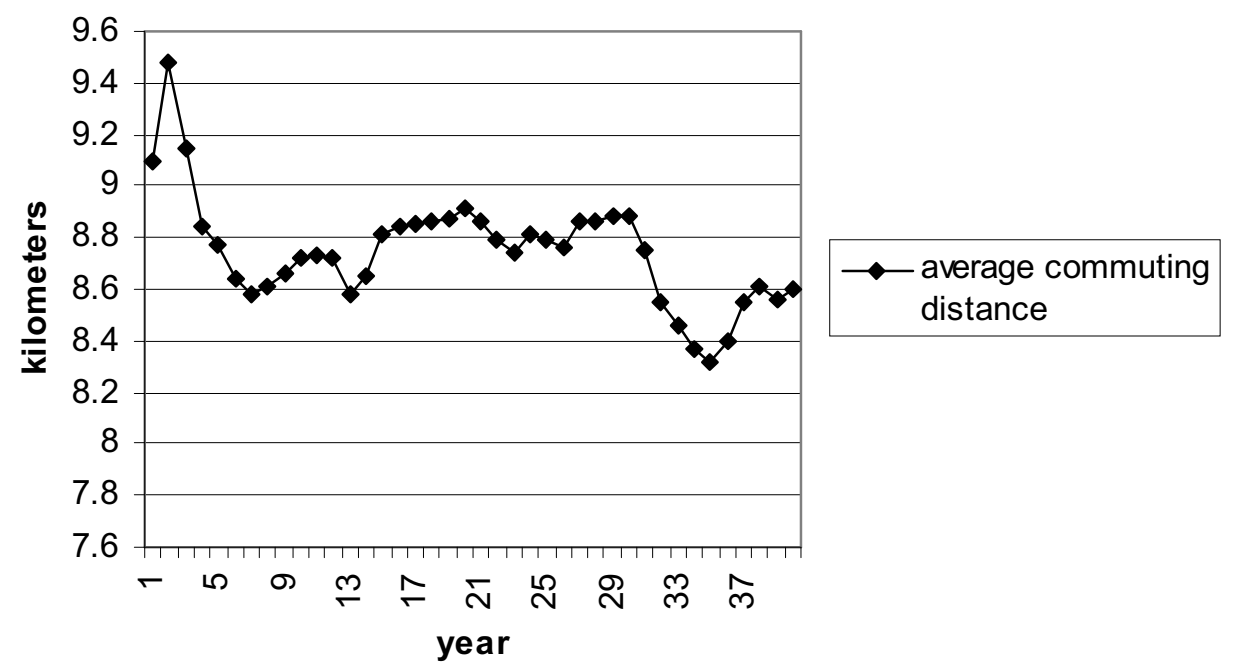

Figure 3 Development of the average commuting distance

The extended model can be used to simulate a worker's career. For this purpose we use the same specification of the wage offer distribution as was employed above for the model with layoffs. Now we assume that there are no layoffs and that job offers arrive with a fixed rate of 1/12 per month. All 500 workers start with the unemployment benefit and without a job. They work (or search for a job) for 40 years. During this period there preferences remain unchanged. ${ }^{9}$ In our simulations, all searchers usually had accepted a job within 7.5 years. Mobility on the labor market is decreasing over the time as a consequence of decreasing acceptability of job offers.

\footnotetext{
${ }^{9}$ This implies, for instance, that end of working life effects on job acceptance behavior are absent.
} 
There are 2126 accepted job offers, which implies that workers switch job three times after they have accepted the first job. Of these accepted job offers, 95 involve a decreases in income and in the commuting distance. This implies that almost $6 \%$ of the job switches are realized only because of the shorter commutes that could be realized. Figure 3 shows the development of the average commuting distance among employed workers over time. There is a decrease in the early years, but it should be realized that the number of employed workers is small initially. The first few workers who accept a job have were offered, by coincidence, a relatively high commute. The average commute decreased when more workers accepted a job. Average income is shown in Figure 4. It decreases in the early years, but the same warning as was given for commuting distance applies. In later years there is a gradual increase in income, which is consistent with the fact that workers accept better jobs. The number of job changes decreases over time. Acceptance probabilities for job offers decrease sharply for workers who have already realized one or more improvements over their initial situation. Finally, Figure 5 shows the share of job switches that imply a decrease in both the commuting distance and income in the total number of changes. This share increases initially because job switches can only be realized after a first job has been accepted. The share seems to be higher between periods 25 and 35, but decreases toward the end of the 40-year period. So no clear pattern emerges.

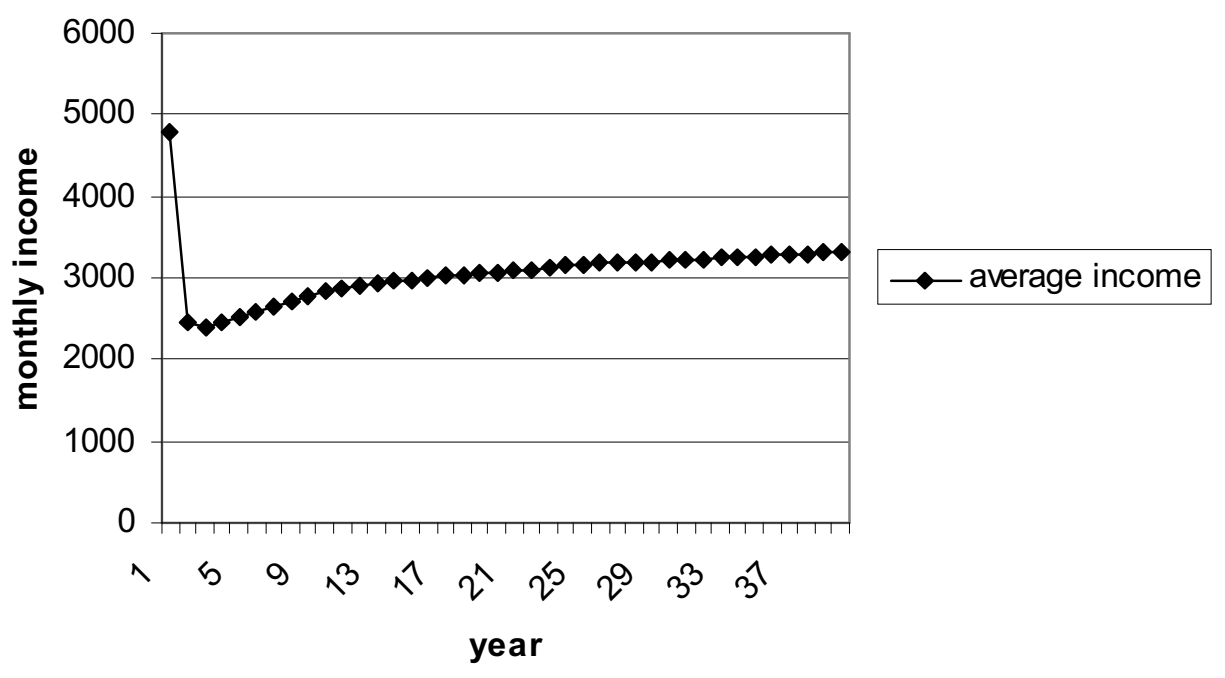

Figure 4 Development of income

In this model with on-the-job search workers with longer commutes have (all else equal, including income) a higher probability of accepting a job offer than others. However, if we regress the new commuting distance on the old one, we find:

$$
r_{\text {new }}=8.62+0.0333 r_{\text {old }} \quad R^{2}=0.001
$$

The $\mathrm{R}^{2}$ is virtually equal to zero and the coefficient for the old commuting distance has the wrong sign and is insignificant. Adding income to the equation results in a second insignificant coefficient. We have not constructed a Table, but it should be clear by now that regression to the mean will also in this simulation model result in a large probability that long commutes are 
followed by shorter ones. The effect of this on the average commuting distance is counteracted by the equally large probability that long commutes follow shorter ones and the net result is the insignificant coefficient in the regression equation.

It is somewhat surprising that even in this model, where there are no layoffs and workers with long commutes are willing to give up earnings for a shorter commute, there is no clear tendency towards smaller commutes over time. One of the reasons is that commuting costs play a clear, but limited role in the present model. Space enters the model in two ways. One is, by means of commuting costs, the other is the spatial aspect of the job offering mechanism. The latter implies that the average commuting distance of an offered job is equal to 10 kilometers. The probability that a job will be offered that implies a commute of more than, say, 20 kilometers is therefore small. The consequence of this is that a job offer that implies an increase in earnings of at least the commuting costs of 20 kilometers is almost always acceptable to a searcher. Commuting costs only have substantial effect on the probability of accepting job offers just above the reservation levels.

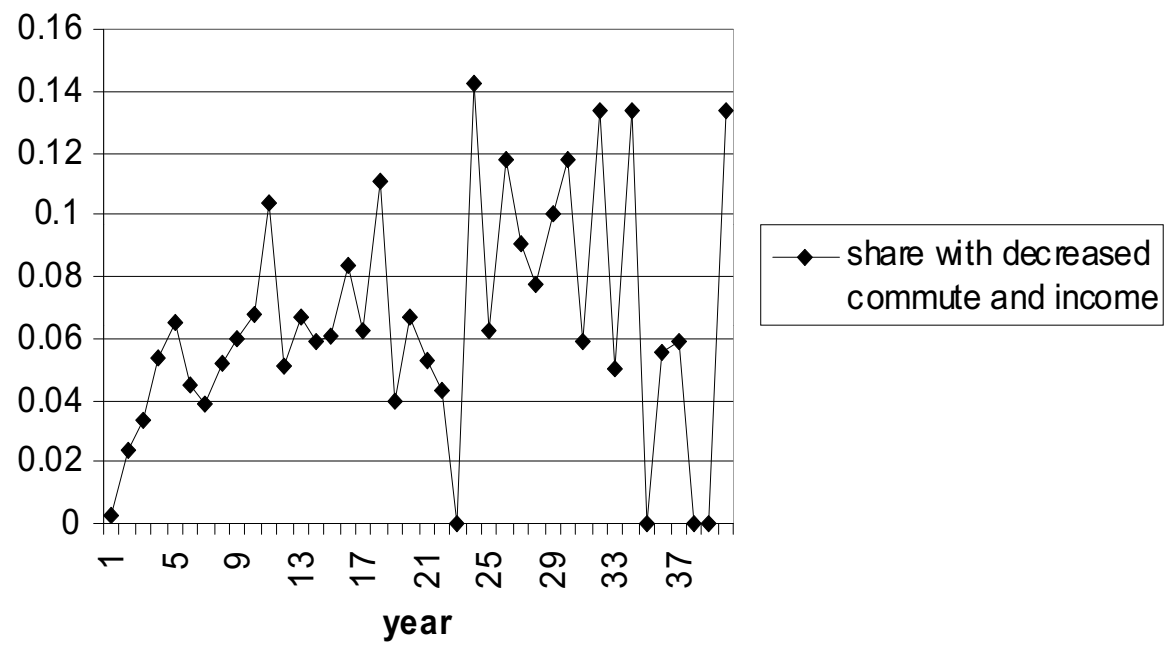

Figure 5 Share of job switches with a decrease in the commuting distance and income

This is illustrated in Figure 6, which refers to the search model with layoffs, but without on-thejob search. The horizontal axis of the figure gives the earnings level of offered jobs. If commuting costs were zero, all offers with earnings at least equal to the reservation level of disposable income would be accepted. The corresponding truncated density is shown in the figure. This truncated density refers to all job offers that pass the first hurdle. The second hurdle refers to the commuting costs: a job offer will only be accepted if the difference between the offered earnings and the reservation level of disposable income exceeds the commuting cost. Figure 6 also shows the density that results after this has been taken into account. It shows that commuting cost makes a difference only when offered earning are relatively close to the reservation level. Job offers implying earnings that are substantially higher than the reservation level are almost always accepted since the probability that commuting costs are prohibitive is negligible. The same phenomenon occurs in the model with on-the-job search. There, job offers 
implying a large increase in income will almost always be accepted because the probability that commuting costs are higher that the increase in income is negligible.

It can be concluded that in the simulation model used here, the spatial aspect of the matching process that determines whether a searcher and a vacancy get into contact with each other is as important as commuting costs for the average commuting distance of accepted job offers. The empirical significance of this spatial aspect of the way searchers and employers get into contact with each other is not completely clear. Rouwendal (1999) used a distance decay effect in his search model, but he cannot distinguish between the effect of the spatial distribution of vacancies and the effect of distance on the spread of information about these vacancies. The spread of information over space depends, of course, on the recruitment channels used by employers and also on the way they select applicants. It is probable that space plays a role, although for the higher educated the effect of distance is probably smaller than for the lower educated. Note also that a smaller variance of the distribution of offered earnings would imply a large role for commuting costs, since most of the 'mass' of the distribution will then be close to the reservation wage and high increases in earning will seldom be realized.

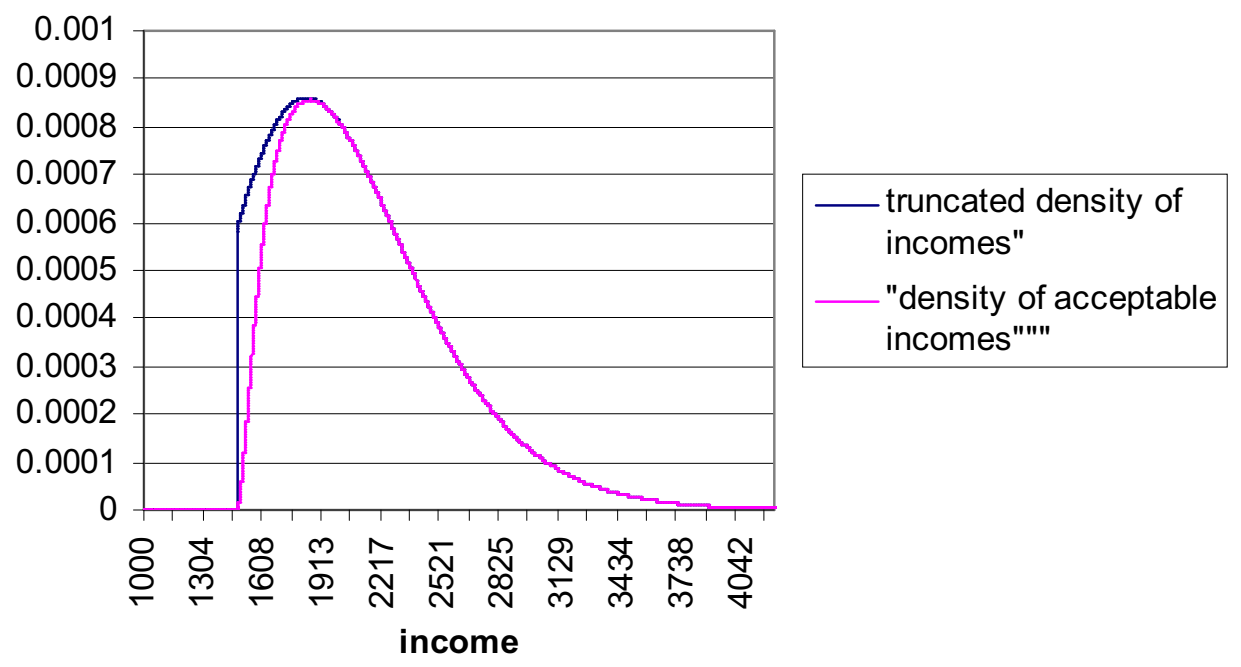

Figure 6 The effect of commuting cost on the distribution of acceptable job offers

\section{A spatial equilibrium model}

The models that have been used thus far consider only one side of the market: they take the distribution of job offers as given, and concentrate on the optimal strategy of the workers. We will now show that this partial model can be embedded in a more general model in which the wage distribution is determined by profit maximizing behavior of employers who take into account the imperfections of the labor market. We do so for what is perhaps the simplest possible setting: an isotropic plane over which workers and jobs are uniformly distributed and there is no on-the-job search. Utility is assumed to be equal to disposable income. All workers and jobs are identical, which means that they will all set the same wage and have the same reservation value of disposable income, respectively. Note, however that the distribution of the disposable income 
of offered jobs is not degenerate because job offers originate from different locations and therefore imply different values the commuting costs and disposable income for the workers. Let the probability that a vacancy will be offered to a worker be proportional to exp(- $\beta r)$, with $r$ the distance between the job and the worker. This means that vacancies that are located further away will have a smaller probability of being offered to the searcher. The probability density that an offered job has commuting distance $r$ is therefore:

$$
f(r)=\frac{r e^{-\beta r}}{\int_{0}^{\infty} s e^{-\beta s} d s},
$$

where it has been taken into account that the number of vacancies is a linear function of the distance from the searcher. ${ }^{10}$ The spatial distribution of offered jobs is then equal to:

$$
F(r)=\frac{\int_{0}^{r} s e^{-\beta s} d s}{\int_{0}^{\infty} s e^{-\beta s} d s} .
$$

The equation for the reservation value of disposable income is (cf. 3.9):

$$
y^{r e s}=b+\frac{\lambda}{\rho+\theta} \int_{0}^{\left(y-y^{r e s}\right) / a}\left(y-a r-y^{r e s}\right) f(r) d r
$$

and can be rewritten as:

$$
y^{r e s}=\frac{(\rho+\theta) b+\lambda F\left(r^{r e s}\right)(y-a \bar{r})}{\rho+\theta+\lambda F\left(r^{r e s}\right)}
$$

where $r^{r e s}=\left(y-y^{r e s}\right) / a$, the maximum acceptable commuting distance and $\bar{r}$ is the average commuting distance of acceptable job offers:

$$
\bar{r}=\frac{\int_{0}^{r^{r e s}} s^{2} e^{-\beta s} d s}{\int_{0}^{r^{r e s}} s e^{-\beta s} d s}
$$

Equation (5.4) says that the reservation level of disposable income is a weighted average of the unemployment benefit and the expected level of disposable income of acceptable jobs.

What we now have to consider is whether it is rational for employers to set a wage level that is at least as high as the unemployment benefit. For this purpose we use the model of employer behavior developed in Rouwendal (1998). With some changes in notation, the expected net present value of the profits of an employer who opens a vacancy and offers a wage $y$ can be written as:

$E(\Pi \mid y)=\frac{c(\rho+\theta)+(k-y) \alpha G(y)}{\rho+\theta+\alpha G(y)}$

\footnotetext{
${ }^{10}$ The reason is that the circumference of a circle is $2 \pi \mathrm{r}$.
} 
where: $c<0$ is the (instantaneous) cost of the vacancy, $k-y$ the profits associated with having the vacancy filled, $\rho$ the employer's rate of discount (for simplicity assumed to be equal to that of the workers), $\theta$ the rate at which the job becomes vacant again, $\alpha$ the rate at which the vacancy is offered to a searcher and $G(y)$ the probability that the employer's wage offer will be accepted. The acceptance probability is equal to the probability that the job will be offered to a searcher whose reservation value is lower than the level of disposable income implied by the job offer. It can be determined as:

$$
\begin{aligned}
G(y)= & \frac{\int_{0}^{r^{r e s}} s e^{-\beta s} d s}{\int_{0}^{\infty} s e^{-\beta s} d s} \\
= & F\left(r^{r e s}\right)
\end{aligned}
$$

Using this result, the profit-maximizing wage (cf. Rouwendal, 1998, eq. 23) can be written as: $y=k-c-\left(1+\frac{\alpha F\left(r^{r e s}\right)}{\rho+\theta}\right) \frac{F\left(r^{r e s}\right)}{\partial F\left(r^{r e s}\right) / \partial y}$

and it is easy to verify that:

$$
\frac{\partial F\left(r^{r e s}\right)}{\partial y}=\frac{1}{a} f\left(r^{r e s}\right)
$$

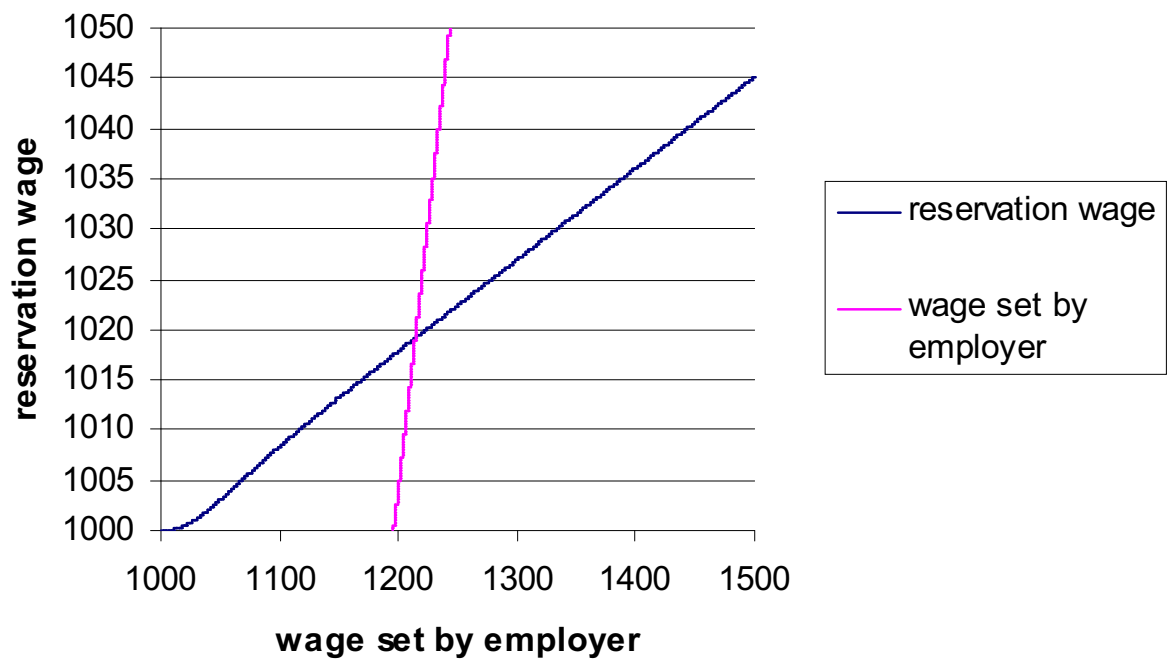

Figure 7 Search equilibrium: numerical example

We now have two equations, (5.4) and (5.8), in two unknowns, $y$ and $y^{\text {res }}$, but since they are nonlinear, it is not obvious that there is a solution. We started ${ }^{11}$ by investigating the question numerically by computing the combinations of reservation levels of disposable income and earnings that are compatible with each other according to (5.4) and (5.8). The numerical values

${ }^{11}$ A more general discussion is provided below. 
are: $b=1000, \mathrm{a}=4, \lambda /(\rho+\theta)=\alpha /(\rho+\theta)=.10, \beta=5, k-c=1600$. The result of the simulation is shown in Figure 7. It shows that the optimal search strategy and the profit maximizing wage setting strategy both imply a positive relation between $y^{\text {res }}$ and $y$. The equilibrium occurs where the two lines cross each other.

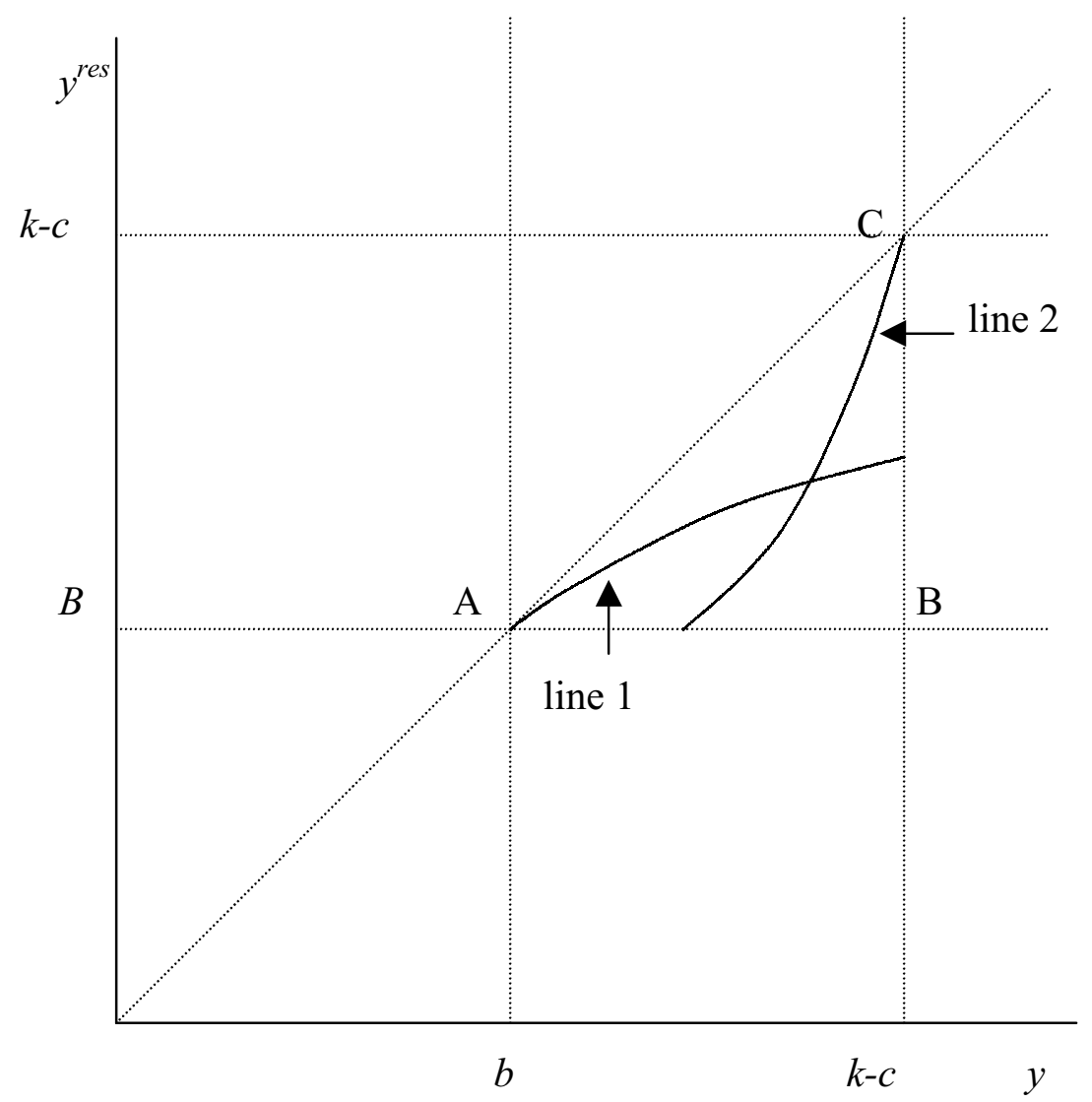

Figure 8 Search equilibrium: general analysis

Reflection on this result suggests that the existence of such an equilibrium is to be expected under general conditions. Equation (5.4) makes clear that the reservation wage is a weighted average of the unemployment benefit and the disposable income of the average acceptable job. It will therefore be at least equal to $b$ and at most to $y$. Equation (5.8) shows that the wage set by employers will be at most equal to $k-c$. It is also clear that it makes no sense for employers to set the offered wage lower than the reservation value of disposable income. Now consider Figure 8 , which has offered income $y$ on the horizontal axis and the reservation level of disposable income $y^{r e s}$ on the vertical axis. The discussion above makes clear that the relevant range for both variables is the interval $[b, k-c]$. Moreover, the offered wage must be at least as high as the reservation value of disposable income. This means that the relevant area of the figure is the triangle $\mathrm{ABC}$. Line 1 pictures the optimal reservation wage as a function of the wage set by employers. When this wage is equal to $b$ the reservation wage will also have this value. For higher wages set, the reservation wage will also be higher, but as a weighted average of unemployment benefit and average disposable income of acceptable job, line 1 is strictly below 
the diagonal AC. Line 2 pictures the optimal wage set by employers as a function of the reservation wage. If the latter is equal to $k$-c , this is also the optimal wage. For lower values of $y^{r e s}$ the optimal wage will be lower than $k$-c , but higher than $y^{\text {res }}$ (setting the offered wage very close to reservation wage would imply an extremely small recruitment area and therefore a long duration of vacancies). This discussion implies that line 1 starts at $\mathrm{A}$ and crosses the line segment $\mathrm{BC}$ below $\mathrm{C}$. Moreover, line 2 starts at $\mathrm{C}$ and crosses the line segment $\mathrm{AB}$ to the right of $\mathrm{A}$. Since both lines are continuous, this means that they must cross. Hence there must be a unique search equilibrium. It is worthwhile to sum up some characteristics of the spatial labor market equilibrium. The average commuting distance is positive, even though workers and jobs are homogeneous and spread evenly over space. However, commuting distances are limited by $r^{r e s}$, which defines a critical isochrone that no worker exceeds. There is substantial excess commuting in this labor market. Indeed, all commuting could in principle be avoided since workers and jobs are uniformly distributed. The commuting distances subsequently realized by the workers in this market are random drawings for a distribution whose parameters are fixed and will therefore show no development over time, even though regression towards the mean may give such an impression. On the job search has not been introduced into the model, but its consequences appear not too difficult to forecast: the critical commuting distance for unemployed searchers will be larger than in the situation without on-the-job search, but they will tend to decrease over the periods during which a worker remains employed.

Compared to the non-spatial equilibrium search models the one developed here has some remarkable characteristics. Due to the spatial dimension of the market a degenerate wage offer distribution (all employers set exactly the same wage) does not imply a degenerate distribution of disposable wages. For the same reason, a degenerate distribution of reservation wages does not imply that all employers set the offered wage equal to this reservation wage. This suggests that the spatial element involved facilitates the derivation of a search equilibrium. In the non-spatial equilibrium search model of Burdett and Mortensen (1998) on-the-job search is a crucial characteristic, as is the assumption that there is a non trivial-interval of wages that are all maximizing the steady state profit of identical firms. This suggests that further exploration of spatial equilibrium search models may be quite worthwhile.

\section{Conclusion}

In the previous sections the usefulness of search theory as a tool for analyzing urban labor markets and commuting behavior has been illustrated in various ways. Using search theory it is possible to derive critical isochrones as a model outcome, to explain excess commuting, to highlight the development of commuting distances over time and to develop an equilibrium model of a simple spatial labor market where the average commuting distance is positive even though all workers and jobs are identical and spread evenly over space.

It was mentioned in the beginning of this paper that search theory is an extremely important tool in modern theoretical and empirical labor economics. Although economic geographers and economists have not completely neglected this item, the topics discussed in the present paper suggest that it this tool may be as valuable for analysis of the spatial dimension of the labor market as it has been for studying the duration of employment, wage distributions et cetera in a non-spatial setting. 


\section{References}

Burdett, K. and D.T. Mortensen (1998) Wage Differentials, Employer Size and Unemployment International Economic Review 39 257-273.

Clark, W.A.V., Y. Huang and S. Whithers (2003) Does Commuting Distance Matter?

Commuting Tolerance and Residential Change Regional Science and Urban Economics 33 199-221.

Fujita, M. (1989) Urban Economic Theory Cambridge University Press, Cambridge.

Getis, A.(1969) Residential Location and the Journey from Work," Proceedings of the Association of American Geographers, 1 55-59.

Gillen, W.J. and A. Guccione (1993) Search and Fetter's law of markets Geographical Analysis 25 165-170.

Gordon, P., H.W. Richardson and M.-J. Jun (1991) The Commuting Paradox: Evidence from the Top Twenty Journal of the American Planning Association 57 416-420.

Gordon, P. and Wong, H.L. (1985) The Cost of Urban Sprawl: Some New Evidence Environment and Planning $A 17$ 661-666.

Gunn, H. (2001) Spatial and Temporal Transferability of Relationships between Travel Demand, Trip Cost and Travel Time Transportation Research E 37 163-189.

Hamilton, B.W. (1982) Wasteful Commuting Journal of Political Economy 90 1035-1053.

Harwitz, M., B. Lentnek, P. Rogerson and T.E. Smith $(1998,2000)$ Optimal Search on Spatial Paths with Recall, Thoeretical Foundations and Computational Procedures and Examples Papers in Regional Science 77 301-327 and 79 293-305.

Levinson, D.M. and A. Kumar (1994) The Rational Locator: Why Travel Times Have Remained Stable Journal of the American Planning Association 61 458-469.

Maier, G. (1993) The Spatial Search Problem: Structure and Complexity Geographical Analysis $25242-251$.

Miller, H.J. (1993) Modelling Strategies for the Spatial Search Problem Papers in Regional Science 72 63-85.

Mills, E.S. (1998) Excess Commuting in U.S. Metropolitan Areas, pp. 72-83 in L. Lundqvist, L.-G. Mattson and T.J. Kim (eds.) Network Infrastructure and the Urban Environment Springer, Berlin.

Mills, E.S. and B.W. Hamilton (1984) Urban Economics Scott, Foresman and Company, Glenview.

Rouwendal, J. and P. Rietveld (1994) Changes in the Commuting Distances of Dutch Households Urban Studies 31 1545-1557.

Rouwendal, J. (1998) Search Theory, Spatial Labor Markets and Commuting Journal of Urban Economics 43 1-22.

Rouwendal, J. (1999) Spatial Job Search and Commuting Distances Regional Science and Urban Economics 29 491-517.

Rouwendal, J. and A. van der Vlist (2002) A Dynamic Model of Commutes, Discussion paper 026/3 Tinbergen Institute, Amsterdam.

Simpson, W. (1980) A Simultaneous Model of Workplace and Residential Location Incorporating Job Search Journal of Urban Economics 8 330-349.

Simpson, W. (1992) Urban Structure and the Labour Market Clarendon, Oxford.

Stigler. G. (1961) The Economics of Information Journal of Political Economy 69 213-225.

Small, K.A. and S. Song (1992) "Wasteful" Commuting: A Resolution Journal of Political Economy 100 888-898.

Van Ommeren, J., P. Rietveld and P. Nijkamp (1997) Commuting: In Search of Jobs and 
Residences Journal of Urban Economics 42 402-421.

Zax, J.S. (1991) Compensation for Commutes in Labor and Housing Markets Journal of Urban Economics 30 192-207. 